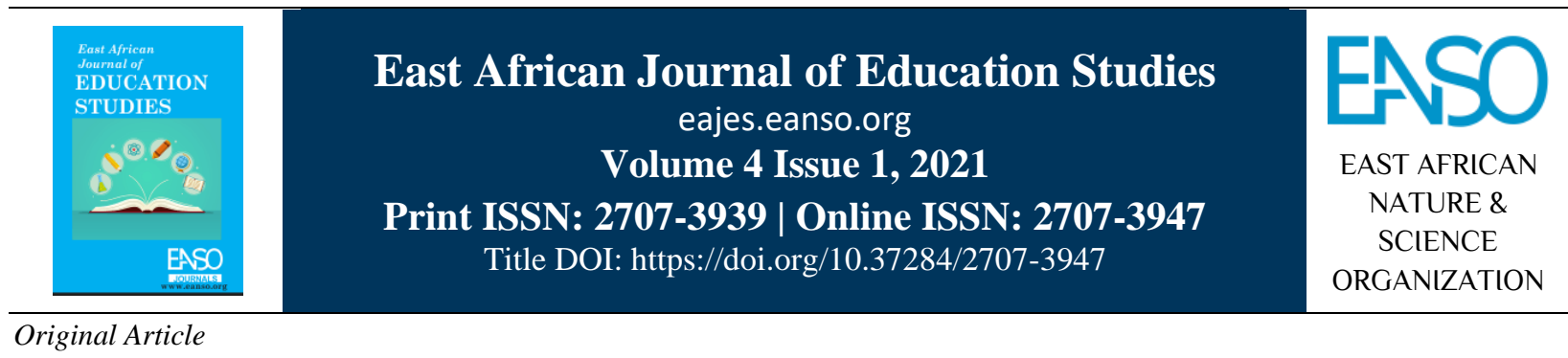

\title{
Gender and Access to Higher Education among Refugees in Dadaab and Kakuma Kenya: Challenges and Possible Interventions.
}

\author{
Dr. Teresa Mwoma, PhD ${ }^{* 1}$ \& Fatuma Chege ${ }^{1}$ \\ ${ }^{1}$ Kenyatta University, P. O. Box 43844-00100, Nairobi, Kenya. \\ *Author for Correspondence Email: mwoma.teresa@ku.ac.ke.
}

Article DOI: https://doi.org/10.37284/eajes.4.1.435

\section{Date Published: ABSTRACT}

13 October 2021 Education plays a critical role in rebuilding societies torn apart by conflicts and violence that are often driven by socio-economic injustices and political

Keywords: differences. This makes people both young and old flee their homes and

Access to Higher

Education,

Borderless Higher

Education,

Education in

Emergencies,

Gender,

Education,

Higher Education for

Refugees. countries to seek refuge in other places ending up in refugee camps. While children in refugee camps are able to access some form of education at lower levels of learning, more male youth than their female counterparts tend to seek post-basic education outside the confines of refugee camps. Statistics show an increase of youth attending secondary school from 4\% in 2011 to $10 \%$ in 2017. However, there were fewer young women than men accessing higher education in 2016, thus creating a gender disparity in favour of men with thirteen out of 91 students enrolled in tertiary education being female while 78 were males. This article, therefore, explores the challenges experienced in accessing higher education by both female and male refugees, as well as provides suggestions on enhancing gender equity in participating in higher education. The article is informed by findings from a desk review on the implementation of the Borderless Higher Education for Refugees (BHER) in Dadaab and the Quality Secondary Education in Emergencies (QSEE) in Kakuma. The article further utilises findings from responses to an unstructured questionnaire that was administered to students undertaking the two programmes to explore their perceptions on challenges experienced in accessing higher education by refugees. Findings indicated that refugees face a myriad of challenges that compromise their ability to access higher education including, early marriages for girls, lack of scholarships to enable them to access education, limitation of movement which hinder them from joining other students in universities where they are enrolled for open learning.

18 This work is licensed under a Creative Commons Attribution 4.0 International License 
APA CITATION

Mwoma, T., \& Chege, F. (2021). Gender and Access to Higher Education among Refugees in Dadaab and Kakuma Kenya: Challenges and Possible Interventions. East African Journal of Education Studies, 4(1), 18-28. https://doi.org/10.37284/eajes.4.1.435.

\section{CHICAgO CITATION}

Mwoma, Teresa, and Fatuma Chege. 2021. "Gender and Access to Higher Education among Refugees in Dadaab and Kakuma Kenya: Challenges and Possible Interventions". East African Journal of Education Studies 4 (1), 18-28. https://doi.org/10.37284/eajes.4.1.435.

\section{HARVARD CITATION}

Mwoma, T., \& Chege, F. (2021) "Gender and Access to Higher Education among Refugees in Dadaab and Kakuma Kenya : Challenges and Possible Interventions”, East African Journal of Education Studies, 4(1), pp. 18-28. doi: 10.37284/eajes.4.1.435.

\section{IEEE CITATION}

T. Mwoma, \& F. Chege, "Gender and Access to Higher Education among Refugees in Dadaab and Kakuma Kenya: Challenges and Possible Interventions”, EAJES, vol.4, no. 1, pp. 18-28, Oct. 2021.

\section{MLA CITATION}

Mwoma, Teresa, \& Fatuma Chege. "Gender and Access to Higher Education among Refugees in Dadaab and Kakuma Kenya: Challenges and Possible Interventions". East African Journal of Education Studies, Vol. 3, no. 1, Oct. 2021, pp. 18-28, doi:10.37284/eajes.4.1.435.

\section{INTRODUCTION}

It is estimated that globally, only one percent of refugee youths and the displaced populations are accessing university education compared to $36 \%$ of young people in other levels of learning (UNHCR, 2018a). For the few young people who are able to pursue higher education, it is believed that it helps them rebuild their future that was disrupted by war, violence and persecution. Enabling such youth to access higher education will strengthen their resilience and self-reliance and build better lives. However, accessing higher education relies on learners attaining good grades in lower levels of learning. Grisanti (2019) observes that lower levels of education are critical in instilling the needed knowledge to facilitate cognitive development among young learners. It is therefore important to provide a firm foundation at the lower levels of learning to ensure the learners acquire the necessary knowledge and skills that will be built on at higher levels of learning (Grisanti, 2019).

Grisanti (2019) further argues that the gender distribution of displaced populations in higher education institutions remains unaccounted for. According to statistics from UNHCR with regard to the refugee population in Kenya, there are 7 girls for every 10 boys in primary school and 4 girls for every 10 boys in secondary school (UNHCR, $2018 \mathrm{~b}$ ). If the trend of dropping 30 percentage points as compared to the boys' attendance were to continue then, there would be only one refugee girl for every 10 boys in higher education in Kenya. That would mean the $1 \%$ statistic would indicate that $0.91 \%$ of displaced men and $0.09 \%$ of displaced women are enrolled in higher education in Kenya (UNHCR, 2018b; Grisanti, 2019).

\section{Barriers to Accessing Education for Women}

Bunyi (2009) observed that the barriers to women accessing education in Africa have been welldocumented and that the trend is shared across the continent Kenya included. According to her, the barriers include socio-cultural beliefs and practices that position women as subordinate to men in the home, community and in the workplace (Bunyi, 2009). In addition, there is an inadequate gender budgeting for girls' education, educational environments that are gender insensitive and unfriendly and insufficient community role models (Lynch and Freeley, 2009; Bunyi, 2009).

Intersectional forms of discrimination in the funding for education for girls and women have been reported to have a direct impact on girls' transition rates to higher levels (Sherab \& Kirk, 2016). Among refugee communities, the situation is complicated by limited scholarship opportunities for refugees and host community youths. This has gradually made online learning programs a welcome option in the provision of further education for refugees as Sherab \& Kirk document 
in Jordan (2016). However, there are specific barriers identified for entry into universities for refugees in Kenya which include, high fees, as well as a high cost of living that refugees are not able to afford. Lack of documentation such as certificates acquired in high school that might have remained in the country of origin and the need for travel documents to enable refugees to travel within Kenya exacerbate the situation for refugee youth in pursuing higher education. The situation may be worsened further for refugee women, as other factors such as gender-related challenges and culture hamper their access to higher education, as noted by UNHCR (2011), whereby fewer young women refugees than men were accessing higher education in 2011 in Kenya.

The violence that includes gender-based violence (GBV) is recognised as a public health and human right concern that is a major obstacle to development (WHO, 2005). Violence against refugee women who may not be independent for their daily survival and who lack knowledge of citizenship rights may yield comparatively more devastating results for those who wish to access education, including transitions to higher education. As among the general populace, such violence has been associated with poverty, lack of education, and gender inequality, as well as the spread of HIV/AIDS (WHO, 2005). Giles (2018); Jones and Naylor (2015) maintain that fear of sexual violence and associated psychological and physical trauma and early marriage are among the reasons young women, girls and their parents avoid school. According to WHO (2005), gender-based violence has been categorised to capture the physical, sexual, emotional and intimate-partner related. Physical violence involves a woman being hit, slapped, pushed, burnt or has her hair pulled. Sexual violence refers to when a woman has been physically forced to have sexual intercourse or having sexual intercourse because of being afraid of what the partner might do to her. Emotional violence on the other hand, is where one feels humiliated or belittled or being scared or intimidated. Intimate-partner violence is where a woman has encountered all the above forms of violence in the hands of an intimate partner.

Limited access and lack of educational opportunities may make marginalised women more vulnerable and susceptible to gender-based violence (WHO, 2005). While there may be no clear explanation about the link between gender-based violence and women's access to higher education, in our view, it is reasonable to assume that the experiences of gender marginalisation in lower levels of education, coupled with gender-based violence within the school and outside school may constitute factors that contribute to low female access to higher education. For instance, dropping out of school due to pregnancy or gender bullying contribute to fewer girls completing schooling compared to boys. Pittaway and Bartolomei (2001) argue that in refugee contexts, women are more vulnerable to violence and discrimination due to their race and gender. They maintain that in countries of resettlement, priority in accessing education and employment is given to men rather than women hence further marginalising women who are already marginalised by virtue of being refugees.

Martin (2004) maintains that from the 1970s, UNHCR and other humanitarian organisations have recognised the special needs of refugee women who have found themselves vulnerable to sexual and gender-based violence. As well, according to the UNHCR Handbook for the protection of women and girls, UNHCR has the responsibility to promote gender equality as well as eliminate violence against women and girls in refugee contexts (UNHCR, 2008; Grabska, 2011). However, it is not known why, thirty years on, refugee women and girls are still impacted by gender-based violence and other forms of gender discrimination in their struggles to access secondary and university education. This article presents insights from refugee students' perceptions on male and female access to higher education.

\section{METHODOLOGY}

The findings presented in this article were derived from a desk review involving the review of reports and publications from the Borderless Higher Education for Refugees (BHER), as well as findings from a non-structured questionnaire administered to students undertaking a diploma in secondary education under Quality Secondary Education in Emergencies (QSEE) in Kakuma and those taking a bachelor's degree under BHER project in Dadaab. 
As part of course feedback, in July 2019, we administered a questionnaire to thirty-six male students and six female students who were pursuing either a diploma or degree courses at Kenyatta University in the Dadaab and Kakuma camps. The questionnaire had four questions designed to elicit participants' perceptions in relation to refugee women and men's access and their performance in academics; identifying factors and challenges that prevent refugee women and men from accessing higher education; and perceived interventions to mitigate the highlighted challenges. The questionnaire further sought to find out what motivated refugees to pursue higher education. The forty-two participants involved in the study were comprised of 23 BHER bachelors of education students in Dadaab and 19 QSEE diploma students in Kakuma. The questionnaire generated qualitative data, which was analysed thematically.

The BHER is a partnership programme offered to refugee students in Dadaab Garissa County, Kenya since 2014. Dadaab is currently hosting three refugee camps, namely Dagahaley, Ifo and Hagadera. Residents in the three refugee camps arrived in Kenya in the 1990s. The first refugee camp was established in 1991 occasioned by the influx of refugees fleeing civil wars in Somalia. The second wave of the influx was witnessed in 2011 following severe drought and famine in Southern Somalia.

The QSEE is a partnership project offered to refugee students in Kakuma in Turkana County since 2018. Kakuma is home to approximately 160000 refugees drawn from Southern Sudan, Sudan, the Democratic Republic of Congo, Uganda, Somalia, Burundi, and Ethiopia. Residents in Kakuma refugee camps arrived in Kenya in 1992 (International Finance Corporation, 2018).

\section{FINDINGS}

\section{Gender and Participation in the Borderless Higher Education for Refugees at Kenyatta University}

The Borderless Higher Education for Refugees (BHER) is a development project that was initiated in Kenya's Dadaab region to improve the quality of education at the primary and secondary levels in refugee camps and local host communities (Giles, 2018). The project was implemented by partner institutions of higher learning, as well as nonacademic institutions drawn from Canada and Kenya. The BHER project utilises a blended mode of learning involving online and onsite facilitation of courses. This has made it possible for refugee youth to access higher education without much movement from their residential places.

\section{Students Enrolled for BHER}

The information utilised in this article will focus on BHER students who were enrolled to take diploma and degree courses at Kenyatta University (KU). It was clear from the start of the BHER project that there was a gender disparity among those who could access higher education. Men in the Dadaab camps had outnumbered women for some time in access to any of the university programs available to aspiring students. Thus, it was not a surprise that men also outnumbered women in accessing the KU programs associated with the BHER project. Table 1 below gives a breakdown of women's and men's participation in KU programs.

Table 1: Kenyatta University BHER project enrolment

\begin{tabular}{lllllll}
\hline & Admission Rate & \multicolumn{5}{c}{ Dropout Rate } \\
\cline { 2 - 7 } Course & Total & Female & Male & Total & Female & Male \\
\hline Diploma & 82 & 15 & 67 & 14 & 2 & 12 \\
B.ED. & 98 & 13 & 85 & 23 & 0 & 23 \\
Total & $\mathbf{1 8 0}$ & $\mathbf{2 8}$ & $\mathbf{1 5 2}$ & $\mathbf{3 7}$ & $\mathbf{2}$ & $\mathbf{3 5}$ \\
\hline
\end{tabular}

Source: derived from internal KU BHER project enrolment data

Throughout the BHER project, 180 students were enrolled at Kenyatta University to pursue either diploma or degree courses. Table 1 shows that there was a $15 \%$ female enrolment for diploma and degree courses while $85 \%$ were male. The table further shows that only two female students dropped out of the project denoting a $93 \%$ retention of females who were enrolled in the KU programs. The 
high retention rate could be attributed to interventions that were put in place to ensure that women are supported to pursue their higher education. The interventions utilised to increase female participation in the BHER project include:

- Encouraging nursing mothers to bring their children to the Learning Centre during intensive terms.

- Encouraging nursing mothers or women with children to bring a family member or friend to assist with child care, the cost of which was covered by the BHER Project.

- Providing a special room in the residential compound of the Learning Centre for breastfeeding mothers and their caregivers.

- Providing sanitary towels free of charge to all women

- Providing second chances to women who may have missed courses or terms due to pregnancy, childbirth, or home responsibilities.

- Providing counsellors for female students who served as advocates for them with faculty when they had failed to submit assignments or needed extensions.

These interventions played a critical role in ensuring female students enrolled in the $\mathrm{KU}$ programs were retained and continued to pursue higher education. However, given the small percentage of women enrolled in the BHER project, we sought to further explore student's perceptions on the factors that contribute to the disparity in enrolment for refugee females and males in higher education. Findings from the course feedback are presented in the sections below.

\section{Challenges Faced by Female Refugees in Accessing Higher Education}

In trying to understand how refugees perform in higher education, participants were asked to state what they perceive to be the main reasons for refugee female students' performance in primary and secondary education, which forms the basis for their admission to higher education. Findings from participants' responses revealed that boys are perceived to perform better than girls in primary and secondary levels for various reasons including responsibility for domestic work, where girls are assigned more household chores to do at home than boys. The result is that girls have less time to study and attend to their educational tasks and assignments. Health challenges associated with menstruation were also identified as reasons that led to some girls missing school during their menstrual period, thus contributing to poor academic performance. These findings agree with the argument of some NGOs and international agencies that low enrolment and the retention of refugee women and girls in school is due to household gender relations, menstruation and early pregnancy (Giles, 2018). The overall gender sensitivity of the male students, as evidenced in the quotes below, is exceptional and may be related to their several years of exposure to gender equity norms in the BHER related university programs.

Participants also revealed that parents invest more in male youth's education compared to female youth, the latter who was reported to be married off early and therefore not given an opportunity to pursue education or attend school regularly hence lowering their academic performance. It was further reported that girls engage more in household chores hence do not have adequate opportunities for school-related group discussions during and after school like boys do. These experiences, according to participants, coupled with a lack of role models and mentors in the camps contribute to girls' poor performance in school.

"Boys are normally not engaged in domestic work therefore have enough time to concentrate on their books while girls engage in domestic work like cooking, fetching water, and collecting firewood. Girls in the refugee community are busy with household chores so they have no time to learn. Others are married off while still young" (Male respondent KKM).

"In Dadaab refugee context, parents invest a lot of time, wealth and commitment on boys compared to girls though there is rapid transformation these days where the number of educated girls is increasing yet there is a gap" (Male respondent DDB). 
"Some women are required to look for food for their children and siblings. Men feel that they are superior hence can force women to stay at home" (Female Respondent).

It is apparent from the above sentiments that as much as household chores are important to ensure girls are inducted into the world of work at home, it is likely to impact negatively in the education of girls and young women as they are not likely to have enough time to study. This on the other hand leaves boys and young men to concentrate on educational activities such as homework, and participation in other student activities, hence improving their chances of performing well in basic education (primary and secondary education) which is a pathway to join higher education.

Poor performance in secondary school was identified as limiting girls' access to higher education where those who did not attain the minimum grade of $\mathrm{C}+$ requirement are prevented from pursuing higher education in Kenyan universities. "Some refugee girls and boys perform poorly in primary and secondary education hence they do not attain a grade that can allow them access higher education career selection" (Male respondent KKM). These assertions are consistent with Giles (2018) argument that few women in Dadaab camps are eligible for Kenyan university programs because of their inability to achieve an overall entry grade of $\mathrm{C}+$ in their secondary education.

Families were reported to be committed to young men's education but not young women's education. Early marriage was cited as a factor that contributes to girls not pursuing higher education:

"Most girls are married off between the ages of 15 -22 years, while the few educated are despised and some are not employed. Early and forced marriages, therefore, make girls not pursue their education" (Male respondent DDB).

"Community negligence in refugee camps have also contributed as people in camps have negative attitudes towards education for girls. The majority of the families marry their daughters off after high school as parents consider higher education for boys than girls" (Male respondent KKM).

Women refugee students revealed that early marriages driven by poverty and protection needs as expressed by parents are a challenge that discourages women from pursuing education:

"Most women do not access education due to early marriages driven by poverty whereby some girls either are married while they are still young or they engage in domestic work to earn a living for their families" (Female Respondent).

"Early marriage, poverty, forced marriage, cultural practice[s] like FGM contribute to girls not going to school" (Female Respondent).

According to female participants, girls are forced to drop out of school to get married. They further maintained that poverty drives parents to allow their daughters to do domestic work within the camps to earn income to support their families. One female respondent revealed this by saying:

"Poor families face challenges in feeding their children hence parents prefer their daughters to work as house girls [domestic workers] in order to earn income for the family" (Female Respondent).

Poverty and poor performance in lower levels of learning were identified to be negatively contributing to female refugees' participation in education.

\section{Mitigating the Challenges Faced by Female Refugees in Accessing Higher Education}

In order to overcome the challenges outlined above, participants were asked to highlight some of the mitigation measures that could be put in place to enhance participation in education. Overall, students expressed the value of sensitising the Dadaab (DDB) and Kakuma (KKM) refugee communities on the importance and benefits of educating girls and young women. More specifically, participants identified various measures to be put in place including the need for women to be economically empowered to enable them to meet their children's and families' basic needs which are perceived to be very important: 
"Lack of concentration in education is caused by poverty because if the mother is settled economically, she can deal with other situations. So, I suggest that all female students be supported with livelihood projects so that they can continue with their studies" (Female Respondent).

The provision of remedial classes for girls and women while in primary and secondary school was identified as a makeup for time lost in domestic and other work and thus can enable them to acquire qualifying grades for higher education: "Girls and women should be provided extra remedial classes to improve their performance so that they can access high education" (Male respondent KKM).

The sensitisation of parents on the importance of school over marriage was reported as a path to higher education:

"Parents should delay marriage for their daughters so that girls can go for higher education. Parents should be made aware and sensitised on the importance of educating girls. Girls and women education should be supported by parents and all stockholders" (Male respondents DDB).

Family planning for women was identified as one of the measures that should be emphasised that will enable women to pursue their education. Women should be encouraged to participate in education even if they are married or not. They should be encouraged to use family planning in order not to be so burdened in caring for children while studying (Male respondent DDB).

More scholarships targeting women, provision of sanitary towels were other measures identified that could support more women access to higher education. "Offering [more] scholarships to women"; "community mobilisation to encourage women to strive for higher education"; the provision of sanitary materials for girls" (Female respondents)

\section{Opportunities and Challenges Faced by Men in Accessing Higher Education}

Similar to the questions asked about the experiences of women, participants were asked to indicate the factors motivating refugee men to pursue higher education. The factors identified include aspirations for a bright future, the availability of scholarships and family responsibility.

Standards of living and aspiration for a bright future in terms of getting a good job and having a good career were perceived as a motivation for refugee men to pursue higher education. This coupled with a desire to become role models to young children further motivated refugee men to pursue higher education:

"The motivating factor that make[s] young people pursue higher education is the standards of living in the camp. Young refugees tend to [want to] achieve their dreams and ambition and hope of having a good future which motivates them to pursue higher education" (Male Respondents KKM).

"To get a better job in future, to have a better career like professors, doctors or to have a better standard of living all motivate men to pursue education. Young refugee men are motivated to become role models to their communities. They are aware that higher education is important for the changes of their environment" (Male Respondents KKM).

Men also aspire to pursue higher education to gain knowledge and skills that will enable them to participate in developing their home countries when repatriated. One respondent reported this by saying: "The development of Somali country requires me to pursue education to go back and rebuild my country" (Male Respondent DDB). Accessing available scholarships was expressed as a motivating factor for refugee men. Not only do scholarships provide income, which can supplement impoverished livelihoods in the camps, but they open the door to higher education for young men:

"In my view, what can motivate refugee men to access higher education after secondary school is offering many scholarships because with many scholarships it will motivate them to pursue their higher education" (Male Respondent KKM). "Availability of the sponsorship, make[s] accessibility of university education possible for refugee men" (Male Respondent DDB). 
While the availability of scholarships was seen as a motivation for young men, it was apparent that some scholarships focus on the pursuit of a specific career choice, which is not the preference of the student or is limited by age. Thus, older refugee men may have a more difficult time accessing higher education. "The scholarships available restrict people to choose a career they need [but] everyone [wants] a career of his choice" (Male Respondent KKM). "Male refugees have a challenge of few scholarships which do not only have high pass marks but also limited to a certain age, yet many of the men refugees [want] opportunities to study while in the camp at old age" (Male Respondent KKM). In addition, scholarships are advertised online and many aspiring refugee students are not able to access them as they do not know how to use computers, or due to lack of internet connectivity: "Some of the scholarships are offered online, which is a challenge for many youths in the community because most of them do not know how to use computers or do not have smartphones" (Male Respondent KKM).

Family responsibility for parents, spouses and children, whether current or in the future was indicated as another motivating factor by refugee students interested in the pursuit of higher education. Men viewed themselves as providers for their families:

"For my case, I am taking higher education because of my responsibility as a man. One day, I will have a wife and children and will cater for them. Another reason is the burden of parents and siblings. Being the only child in the family with education, the family members look upon me as a provider. According to our community, men are viewed as the providers of every material needed. So, most of them are brought up knowing that they are supposed to strive and provide for their future families" (Male Respondents, KKM).

A desire to pursue the education that would in turn enable them to acquire better jobs to earn a living to meet their roles as a household provider was central for those men who had chosen to pursue a university education. Although family responsibility acts as a motivation for men to pursue education, they reported that they were sometimes not able to find time, as well as raise funds, to pursue higher education:

"Due to the demanding responsibilities men carry in their families they are not able to pursue higher education. Some men have large families who depend on them to get the basic needs such as food, water so it is hard for them to further their studies" (Male Respondent KKM).

"Most of these men have families to look after, so they are put in a dilemma of either to study or look for money to support their families" (Male Respondent KKM).

In addition to the above familial issues, early marriage and lack of parental care were said to impact the possibility for young refugee men to attend university. Increased parental responsibilities or lack of parents, leaving young men to have to fend for their children, or fend for themselves (as unaccompanied refugee youth) were defined as significant barriers:

"Early marriage, lack of parental care, and peer pressure prevent refugee men from pursuing higher education" (Male Respondent KKM).

Early marriage which makes[s] men look for daily bread [plus] a lot of responsibilities which [are] a hindrance to refugee men to pursue higher education. Some think that education is for only the youth" (Male Respondent KKM).

Two other areas that posed challenges for refugee men who desired to access higher education were the poor secondary school graduation grades and lack of adequate documentation, as required by Kenyan universities. Low grades and lack of career guidance in secondary schools coupled with losing hope for future success which were perceived to contribute to refugee men not pursuing higher education or being able to access much-needed scholarships:

"Some men performed poorly in their secondary school national examinations. The majority of them come from poor families. Some of them have lost hope for their future due to wars in their homeland hence, they see no importance of learning instead, 
they depend on UNHCR for survival" (Male Respondent KKM).

"Opportunities are limited in terms of scholarships. Their certificates may not meet the criteria for selection. Others may fear to show up because the scholarships are very competitive" (Male Respondent KKM).

The absence of identification cards, as well as academic certificates that allow refugees to apply for entrance to universities outside their refugee camps in Kenya, discourages refugee men from pursuing higher education outside refugee camps. They revealed this by saying:

"Some refugees lost their documents back in their home countries due to war and they lack documentation to get registered in higher learning institutions. Inadequate finance to continue furthering their education and some fear that they will drop out since they do not have enough money to pay for themselves. Those in DRC Congo have challenges to have their documents to be translated into the Kenyan education system" (Male Respondent KKM).

\section{Mitigating the Challenges Faced by Male Refugees in Accessing Higher Education}

Respondents identified various intervention strategies that could be utilised to mitigate the aforementioned challenges affecting male refugees in accessing higher education and these included increasing scholarships; coming up with mentorship programmes, having enhanced internet connectivity, more access to computers in the camps, and the discouragement of early marriages and early sexual contact.

Respondents revealed that there is a need to increase scholarship opportunities to cover diplomas and degrees to enable more refugee men to access higher education. They revealed this by saying:

"My suggestion is to make sure that refugee men are given enough scholarships so that most of them who are idle to access higher education. They should also be provided with enough facilities and resources that will enable them to access higher education. Scholarship requirements should also reduce the grades needed for accessing higher education. So that men with lower grades in KCSE should also have opportunity to go for higher education" (Male Respondent KKM).

"Creating more opportunities in terms of scholarships, extending chances for diploma and degree courses as well as improving studies from online to main campuses" (Male Respondent $\mathrm{KKM})$.

Introducing mentorship programmes on higher education among refugee men and having trained teachers in primary and secondary schools is perceived as one way of enabling many refugees to attain good grades that will enable them to pursue higher education;

"My suggestion is that refugee men should be mentored to enhance their understanding on the importance of accessing higher education. Training teachers in order to improve students' performance will allow them to attain good grades that will enable them access higher education" (Male respondent KKM).

Enhancing internet connectivity and availing computer labs and training refugees on how to use computers to access online learning materials was perceived as one way of facilitating online learning:

"The institutions of higher learning should have at least computer labs and classes so that it can motivate refugee men in their learning. Also, it can help in case of a change to blended learning system in future" (Male Respondent KKM).

Creating awareness on the importance of education and discouraging early marriage among the youth and discouraging early sexual encounters that put them into early responsibility was perceived as one way of helping refugee men pursue higher education;

"By creating awareness on the importance of education thereby improving the quality of education. By discouraging early marriage through general meetings so that men are able to access higher education. By encouraging men to work towards achieving their goals of education to enhance higher education" (Male Respondent KKM).

26 This work is licensed under a Creative Commons Attribution 4.0 International License 
Improving secondary education in the camps by providing the required teaching and learning materials and qualified teachers will enable more refugee men to attain good grades that will enable them to access higher education:

"Improving secondary education in the camps by providing all necessary books, lab apparatus, chemicals for practical and qualified teachers will enable more refugees to acquire grades that will enable them access higher education" (Male Respondent KKM).

It is apparent from the suggestions given above that male participation in education can be supported by adopting strategies such as increasing scholarship opportunities to cover diploma and degree courses, introducing mentorship and career guidance programmes in secondary schools to encourage students to see the importance of attaining good grades to enable them to pursue higher education. Provision of adequate teaching and learning materials in secondary schools as well as enhancing internet connectivity within the camps and learning institutions is seen as one way of enabling more refugee men to access education.

\section{CONCLUSIONS AND COMPARISONS ACROSS GENDER IN ACCESS TO HIGHER EDUCATION}

Participation in higher education cannot be looked at in isolation without considering the underlying factors that motivate women and men refugees to pursue education. Pursuing higher education is a result of learners successfully attaining good grades in lower levels of learning that enables them to enter higher institutions of learning. This article, therefore, makes the following comparative and other conclusions based on the reviewed literature and findings on participants' perceptions.

The challenges encountered by women and men refugees emanate from various sources including cultural beliefs, poor performance in lower levels of learning where girls and boys are not able to attain grades that can allow them access tertiary education. This coupled with society expectations and beliefs that girls should engage in domestic chores while boys are expected to pursue education to fulfil their provision role as breadwinners, complicates the situation making women be more vulnerable and marginalised. Limited scholarship opportunities that are skewed towards the teaching profession as well as limited to specific age limits discourage both male and female refugees who are not keen to pursue a career in education. Early marriages for both male and female refugees were found to add family responsibilities that prevent the young couples from pursuing higher education. Provision of movement documentation and translation of foreign certificates and equating them to the Kenyan education system also seems to be a roadblock to accessing higher education for some female and male refugees.

Given the challenges outlined, there is a need for all stakeholders involved in supporting refugees to come up with measures that will enable many refugees youths to access higher education. The measures could include but are not limited to: (a) Coming up with mentorship programmes that will enable more learners to acquire good grades at secondary levels that can enable them to join higher institutions of learning. (b) Sensitising communities on the importance of educating the girl child and discouraging early marriages and other negative beliefs that girls should assume household chores that take a lot of time that could be used to study. (c) Availing scholarships for both diplomas and degrees will enable many refugee youths to acquire higher education even in middle-level colleges. The scholarship programme should also be flexible to accommodate other careers beyond those pursuing a career in education. (d) Providing movement documents will enable students who qualify for higher education to pursue their studies by joining universities and colleges in different parts of the country.

\section{REFERENCES}

Bunyi, W. G. (2009), Women in Higher Education: A Concern for Development? in Gender, Technology and Development. (3), 407-427.

Giles, W. (2018). The Borderless Higher Education for Refugees project: Enabling refugee and local Kenyan students in Dadaab to transition to university education. 
Giles, W., \& Orgocka, A. (2018). Protracted refugee situations: adolescents in Dadaab, Kenya. In Research Handbook on Child Migration. Edward Elgar Publishing.

Grabska, K. (2011). Constructing 'modern gendered civilised women and men: gendermainstreaming in refugee camps. Gender \& Development, 19(1), 81-93.

Grisanti, E. (2019). Higher education for displaced women: A defense against human trafficking.

Jones, A., \& Naylor, R. (2014). The quantitative impact of armed conflict on education: Counting the human and financial cost. CfBT Education Trust.

Kirk, K., \& Sherab, D. (2016). Access to higher education for refugees in Jordan, Arab renaissance for democracy and development (ARDD)-legal.

Lynch, K., \& Feeley, M. (2009). Gender and education (and employment): gendered imperatives and their implications for women and men: lessons from research for policy makers.

Martin, S. F. (2004). Refugee women. Lexington Books.

Pittaway, E., \& Bartolomei, L. (2001). Refugees, race, and gender: The multiple discrimination against refugee women. Refuge: Canada's Journal on Refugees, 21-32.

UNHCR. (2008). Handbook for the Protection of Women and Girls, Geneva, Switzerland: UNHCR.

UNHCR. (2011). Improving Access to Education for Asylum-seeker, Refugee Children and Adolescents in Central Europe.

UNHCR. (2018a), The other one percent: Refugee students in higher education. DAFI Annual Report 2017.

UNHCR. (2018b), Turn the Tide: Refugee Education in Crisis. Retrieved from https://www.unhcr.org/en- us/publications/brochures/5b852f8e4/turn-tiderefugee-education-crisis.html

World Health Organization. (2005). The World health report: 2005: make every mother and child count. World Health Organization. 